Pacific Journal of Mathematics

A QUASI-KUMMER FUNCTION WZZIR HUSAN ABDI 


\section{A QUASI-KUMMER FUNCTION}

\section{WAZIR HASAN ABDI}

A particular integral of Kummer's inhomogeneous differential equation is obtained when the right hand member belongs to a general class of multiform functions. A few basic properties of the solution function are established.

1. Introduction. Let $\sigma$ be a complex constant but not negative real. We denote by $\mathscr{R}_{\sigma}$ the Riemann surface of $z^{\sigma}$. Suppose $f(z)$ to be analytic everywhere on the disc $K_{R}:|z|<R$, and let

$$
\mathscr{K}_{R}^{o} \equiv\left\{\phi(z) \mid \phi=z^{a} f(z) ; f \text { analytic on } K_{R}\right\} \text {. }
$$

Then, to each element of the multiplier space $\mathscr{R}_{a}$, there corresponds one and only one element of the product space $\mathscr{K}_{R}{ }^{\sigma}$ which is regular everywhere in the domain $K_{R}$ of the analytic component $f(z)$ slit and screwed in the usual way, if necessary. A few subspaces of $\mathscr{K}_{R}{ }^{\circ}$ are:

$$
\begin{aligned}
& \mathscr{K}_{R(\rho)}^{o}:\left\{\phi \mid K_{R}, R \leqq \rho<\infty\right\} \\
& \mathscr{K}_{\pi(p)}^{a}:\{\phi \mid \text { analytic component a polynomial of degree } p\}
\end{aligned}
$$

and

$$
\mathscr{K}_{\infty(k)}^{\sigma}:\left\{\phi|| f^{(m)}(0) \mid \leqq B k^{m},(B, k)>0\right\} .
$$

Now consider the equation

$$
z \frac{d^{2} W}{d z^{2}}+(b-z) \frac{d W}{d z}-a w=\phi(z) .
$$

The associated homogeneous problem leads to Kummer's confluent hypergeometric and other well-known transcendental functions. But the properties of the particular integral of the inhomogeneous equation have been studied in detail only recently by Babister [1] who has considered a few particular cases. In this paper we take the general classes $\mathscr{K}_{R(\rho)}^{\sigma}, \mathscr{K}_{\infty(e)}^{\sigma}, \mathscr{K}_{\pi(p)}^{\sigma}$ and use Frobenius's method to show that in each case a particular integral of (1.1) exists and belongs to some similar subspace of $\mathscr{K}_{R}^{\sigma+1}$. We also give some basic properties of the solution-function which we have called quasi-Kummer.

$$
\begin{aligned}
& \text { As } f(z) \text { is analytic on } K_{R}, \\
& f(z)=\sum_{n=0}^{\infty} \frac{f^{(n)}(0)}{n !} z^{n},|z|<R .
\end{aligned}
$$

Accordingly, a formal series solution of (1.1) is given by 


$$
{ }_{1} A_{1}\left(\begin{array}{l}
\sigma \\
z
\end{array} \mid a ; b(z)\right)=\sum_{n=0}^{\infty} \frac{(\sigma+a+1)_{n} P_{n}(\sigma ; a, b ; f)}{(\sigma+1)_{n+1}(\sigma+b)_{n+1}} z^{n+\sigma+1},
$$

where

$$
P_{n}(\sigma ; a, b ; f)=\sum_{m=0}^{n} \frac{(\sigma+1)_{m}(\sigma+b)_{m}}{(\sigma+a+1)_{m}} \frac{f^{(m)}(0)}{m !}
$$

and $(\nu)_{n}$ denotes the Pochhammer product $\nu(\nu+1) \cdots(\nu+n-1)$.

2. Some subsidiary results. In order to establish our main results, we require some formulae which will be stated in the form of lemmas. For convenience we write:

$$
\begin{array}{ll}
\alpha=|\sigma+a+1| & \lambda=\sec (1 / 2 \arg (\sigma+a+1)) \\
\beta=|\sigma+b| & \mu=\sec (1 / 2 \arg (\sigma+b)) \\
\gamma=|\sigma+1| & \nu=\sec (1 / 2 \arg (\sigma+1)) .
\end{array}
$$

Also, it is assumed that $\alpha, \beta, \gamma$ are all finite and positive.

Lemma 1. For $0<R \leqq \lambda<\infty \operatorname{Max}_{|z|=R}|f(z)|=M(R)$

$$
\left|P_{n}(\sigma ; a, b ; f)\right| \leqq\left[\begin{array}{l}
\frac{(\gamma)_{n} \lambda^{n-1}}{|\beta-\alpha+1|}\left|\frac{(\beta)_{n+1}}{(\alpha)_{n}}+1-\alpha\right| \frac{M(R)}{R^{n}}, \beta-\alpha+1 \neq 0 \\
\frac{(\beta)_{n} \lambda^{n-1}}{|\gamma-\alpha+1|}\left|\frac{(\gamma)_{n+1}}{(\alpha)_{n}}+1-\alpha\right| \frac{M(R)}{R^{n}}, \gamma-\alpha+1 \neq 0 \\
(\gamma)_{n}(n+1) \lambda^{n-1} \frac{M(R)}{R^{n}}, \beta=\gamma=\alpha-1>0
\end{array}\right.
$$

Proof. By Cauchy's inequality

$$
\left|P_{n}(\sigma ; a, b ; f)\right| \leqq \sum_{m=0}^{n}\left|\frac{(\sigma+1)_{m}(\sigma+b)_{m}}{(\sigma+a+1)_{m}}\right| \frac{M(R)}{R^{m}},
$$

which on applying Erber's estimate [3]:

$$
\frac{1}{\left|(\delta)_{n}\right|} \leqq \frac{\sec ^{n-1}(1 / 2 \arg \delta)}{(|\delta|)_{n}},|\arg \delta|<\pi
$$

and after simplification proves the first part of the lemma. The second part follows mutatis mutandis on replacing $\beta$ by $\gamma$. Also in the third case $\left|P_{n}(\sigma ; a, b ; f)\right| \leqq(\beta)_{n} \lambda^{n-1} \gamma \sum_{m=0}^{n} 1 / \gamma+m$. Hence the result.

LEMmA 2. If $\left|f^{(m)}(0)\right| \leqq B k^{m}, B>0, k>0$, then

$$
\left|P_{n}(\sigma ; a, b ; f)\right| \leqq\left[\begin{array}{l}
\frac{B}{\lambda}{ }_{2} F_{1}\left[\begin{array}{c}
\gamma, \beta \\
\alpha
\end{array} k \lambda\right] \quad k \lambda<1 \\
\frac{B l^{n}}{\lambda}{ }_{2} F_{1}\left[\begin{array}{c}
\gamma, \beta \\
\alpha
\end{array} \frac{k \lambda}{l}\right] \quad 1 \leqq k \lambda<l,
\end{array}\right.
$$


Proof.

$$
\begin{aligned}
\left|P_{n}(\sigma ; a, b ; f)\right| & \leqq B\left|\sum_{m=0}^{n} \frac{(\sigma+1)_{m}(\sigma+b)_{m}}{(\sigma+a+1)_{m}} \frac{k^{m}}{m !}\right| \\
& \leqq \frac{B l^{n}}{\lambda} \sum_{m=0}^{n} \frac{(\gamma)_{m}(\beta)_{m}}{(\alpha)_{m} m !}\left(\frac{k \lambda}{l}\right)^{m}, 1 \leqq k \lambda<l
\end{aligned}
$$

which leads to the second part. The proof of the first part is very straightforward.

3. Main Theorems. By Lemma 1 (i), the modulus of the general coefficient in the power-series (1.2) can be majorised by

$$
\frac{(\alpha)_{n}(\gamma)_{n}}{(\gamma)_{n+1}(\beta)_{n+1}}\left(\frac{\lambda \mu \nu}{R}\right)^{n}\left|\frac{(\beta)_{n+1}}{(\alpha)_{n}}+1-\alpha\right| \frac{M(R)}{\lambda|\beta-\alpha+1|} .
$$

Hence the series converges absolutely and uniformly to an analytic function for all $|z|<R / \lambda \mu \nu$. Another majorant is provided by Lemma 1 (ii) both leading to

THEOREM 1. If $\phi \in \mathscr{K}_{R(\lambda)}^{o},(\lambda, \mu, \nu)<\infty$, then ${ }_{1} A_{1}\left(\begin{array}{l}\sigma \\ z\end{array} \mid \begin{array}{l}a \\ b\end{array} ; f(z)\right) \in \mathscr{K}_{R(\rho)}^{o+1}$, $\rho \lambda \mu \nu \leqq R$ and $\left|{ }_{1} A_{1}\left(\begin{array}{l|l}\sigma & a \\ z & b\end{array} f(z)\right)\right|$ never exceeds

$$
\begin{aligned}
& \frac{M(R)\left|z^{\sigma+1}\right|}{\beta \gamma \lambda|\beta-\alpha+1|}\left\{\beta_{2} F_{1}\left[\begin{array}{l}
\gamma, 1 \\
\gamma+1
\end{array} ; \frac{\lambda \mu \nu|z|}{R}\right]+{ }_{3} F_{2}\left[\begin{array}{l}
\alpha, \gamma, 1 \\
\beta+1, \gamma+1
\end{array} ; \frac{\lambda \mu \nu|z|}{R}\right]\right\}, \\
& \beta-\alpha+1 \neq 0
\end{aligned}
$$

or

$$
\begin{aligned}
& \frac{M(R)\left|z^{\alpha+1}\right|}{\beta \gamma \lambda|\gamma-\alpha+1|}\left\{\gamma_{2} F_{1}\left[\begin{array}{l}
\beta, 1 \\
\beta+1
\end{array} ; \frac{\lambda \mu \nu|z|}{R}\right]+{ }_{3} F_{2}\left[\begin{array}{l}
\alpha, \beta, 1 \\
\beta+1, \gamma+1
\end{array} ; \frac{\lambda \mu \nu|z|}{R}\right]\right\}, \\
& \gamma-\alpha+1 \neq 0
\end{aligned}
$$

or

$$
\frac{1}{\beta \gamma \lambda}{ }_{2} F_{2}\left[\begin{array}{l}
\gamma, \\
\gamma+1,1
\end{array} ; \frac{\lambda \mu \nu|z|}{R}\right], \beta=\gamma=\alpha-1>0
$$

Similarly from Lemma 2, we easily obtain

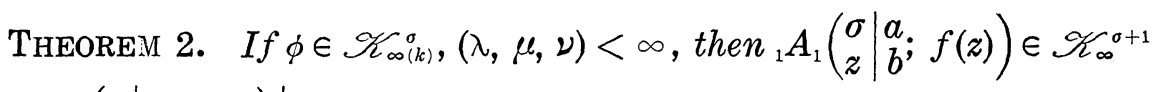
and $\left.\right|_{1} A_{1}\left(\begin{array}{l}\sigma \\ z\end{array} \mid a ; b(z)\right) \mid$ is dominated by 


$$
\begin{aligned}
& \frac{B\left|z^{\sigma+1}\right|}{\beta \gamma \lambda}{ }_{2} F_{1}\left[\begin{array}{l}
\gamma, \beta \\
\alpha
\end{array} ; k \lambda\right]{ }_{2} F_{2}\left[\begin{array}{l}
\alpha, 1 \\
\gamma+1, \beta+1
\end{array} ; \mu \nu|z|\right], k<\frac{1}{\lambda} \\
& \frac{B\left|z^{\sigma+1}\right|}{\beta \gamma \lambda}{ }_{2} F_{1}\left[\begin{array}{l}
\gamma, \beta \\
\alpha
\end{array} ; \frac{k \lambda}{l}\right]{ }_{2} F_{2}\left[\begin{array}{l}
\alpha, 1 \\
\gamma+1, \beta+1
\end{array} ; \mu \nu l|z|\right], 1 \leqq k \lambda<l .
\end{aligned}
$$

Now, if $f(z)$ is a polynomial of degree $p$, then for all nonnegative integers $r, P_{p+r}(\sigma ; a, b ; f)=P_{p}(\sigma ; a, b ; f)$. Hence, denoting the set of nonpositive integers by $Z^{0-}$ we have

TheOREM 3. If $\phi \in \mathscr{K}_{\pi(p)}^{\sigma},(\sigma+1, \sigma+a+1, \sigma+b) \notin Z^{0-}$, then

$$
\begin{aligned}
& { }_{1} A_{1}\left(\begin{array}{l}
\sigma \\
z
\end{array} \mid \begin{array}{l}
a \\
b
\end{array} ; f(z)\right)=\sum_{n=0}^{p-1} \frac{(\sigma+a+1)_{n} P_{n}(\sigma ; a, b ; f)}{(\sigma+1)_{n+1}(\sigma+b)_{n+1}} z^{\sigma+1+n} \\
& +\frac{(\sigma+a+1)_{p} P_{p}(\sigma ; a, b ; f)}{(\sigma+1)_{p+1}(\sigma+b)_{p+1}} z^{\sigma+1+p}{ }_{2} F_{2}\left[\begin{array}{l}
\sigma+a+1+p, 1 \\
\sigma+b+1+p, \sigma+2+p
\end{array} ; z\right] .
\end{aligned}
$$

4. Contiguity relations. As the generalized power series (1.2) is uniformly convergent, a number of interesting contiguity relations can be obtained by applying the operator $d / d z$ or $\delta(\equiv z d / d z)$ termwise. For example

$$
\begin{aligned}
& \frac{d}{d z}{ }_{1} A_{1}\left(\begin{array}{l|l}
\sigma & a \\
z & b
\end{array} ; f(z)\right)=\sigma_{1} A_{1}\left(\begin{array}{c|l}
\sigma-1 & a+1 \\
z & b+1
\end{array} ; f(z)\right) \\
& +{ }_{1} A_{1}\left(\begin{array}{l|l}
\sigma & \begin{array}{l}
a+1 \\
z
\end{array} ; \\
b+1
\end{array} ; \frac{d f}{d z}\right) \text {. } \\
& (b-a-1)_{1} A_{1}\left(\begin{array}{l|l}
\sigma & a \\
z & b
\end{array} ; f(z)\right)=(\sigma+b-1)_{1} A_{1}\left(\begin{array}{l|l}
\sigma & a \\
z & b-1
\end{array} ; f(z)\right) \\
& -(\sigma+a+1){ }_{1} A_{1}\left(\begin{array}{c|c}
\sigma & a+1 \\
z & b
\end{array} ; f(z)\right)+{ }_{1} A_{1}\left(\begin{array}{c|ll}
\sigma+1 & \begin{array}{l}
a \\
z
\end{array} & d f \\
b-1
\end{array}\right) \\
& -{ }_{1} A_{1}\left(\begin{array}{c|c}
\sigma+1 & a+1 \frac{d f}{d z}
\end{array}\right) \text {. }
\end{aligned}
$$

Now, as ${ }_{1} A_{1}$ can be written as

$$
\begin{aligned}
\frac{z^{\sigma+1} f(0)}{(\sigma+1)(\sigma+b)} & +\frac{(\sigma+a+1) z^{\sigma+2}}{(\sigma+1)(\sigma+b)} \sum_{n=0}^{\infty} \frac{(\sigma+a+2)_{n} z^{n}}{(\sigma+2)_{n+1}(\sigma+b+1)_{n+1}}\{f(0) \\
& \left.+\sum_{m=1}^{n-1} \frac{(\sigma+1)_{m}(\sigma+b)_{m}}{(\sigma+a+1)_{m}} \frac{f^{(m)}(0)}{m !}\right\},
\end{aligned}
$$

we have on simplification

(4.3) ${ }_{1} A_{1}\left(\begin{array}{l|l}\sigma & a \\ z & b\end{array} ; f(z)\right)-{ }_{1} A_{1}\left(\begin{array}{c|l}\sigma+1 & a \\ z & ;\end{array} ; \frac{f(z)-f(0)}{z}\right)$ 


$$
=\frac{f(0) z^{\sigma+1}}{(\sigma+1)(\sigma+b)}+\frac{(\sigma+a+1) f(0) z^{\sigma+2}}{(\sigma+1)_{2}(\sigma+b)_{2}} F_{2}\left[\begin{array}{l}
\sigma+a+2,1 \\
\sigma+b+2, \sigma+3
\end{array} ; z\right] .
$$

As particular cases, we see that

$$
{ }_{1} A_{1}\left(\begin{array}{c|c}
\sigma-1 & a \\
z & ;
\end{array} e^{\rho z}\right)=\Lambda_{\rho, \sigma}(a, b ; z) \text { and }{ }_{1} A_{1}\left(\begin{array}{c|c}
\sigma-1 & a \\
z & ; 1
\end{array}\right)=\theta_{o}(a, b ; z)
$$

where $A$ and $\theta$ are Babister's nonhomogeneous confluent functions, so (4.1) and (4.3) reduce to known results [1], (4.236), (4.189). Also from (4.3)

$$
\begin{aligned}
& { }_{1} A_{1}\left(\begin{array}{l}
\sigma \\
z
\end{array} \mid \begin{array}{l}
a \\
;
\end{array}{ }_{p} F_{q}\left[\begin{array}{l}
a_{1}, \cdots, a_{p} \\
b_{1}, \cdots, b_{q}
\end{array} ;\right]\right)
\end{aligned}
$$

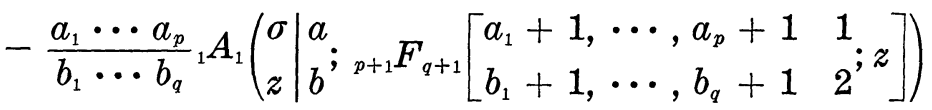

$$
\begin{aligned}
& =\frac{z^{\sigma+1}}{(\sigma+1)(\sigma+b)}+\frac{(\sigma+a+1) z^{\sigma+2}}{(\sigma+1)_{2}(\sigma+b)_{2}}{ }_{2} F_{2}\left[\begin{array}{c}
\sigma+a+2, \\
\sigma+b+2, \sigma+3
\end{array} ; z\right]
\end{aligned}
$$

with the usual restriction on the parameters.

5. Illustration. The above results are of particular advantage when the analytic component of $\phi$ involves functions of hypergeometric type because these (for that matter, almost all) special functions belong to one of the classes considered.

For example: (See Table on next page).

The first four are Babister's nonhomogeneous confluent functions, the next three are obtained via a result due to Carlitz [2]:

$$
\begin{aligned}
{ }_{5} F_{4}\left[\begin{array}{c}
a, 1+a / 2, b, c, d ; \\
a / 2,1+a-b, 1+a-c, 1+a-d
\end{array}\right]_{n} \\
=\frac{(1+a)_{n}(1+b)_{n}(1+c)_{n}(1+d)_{n}}{(1+a-b)_{n}(1+a-c)_{n}(1+a-d)_{n} n !}
\end{aligned}
$$

provided that $a=b+c+d$. In the last two cases $P_{n}(\sigma ; a, b ; f)=$ $\left((\sigma+1)_{n}\right) / n$ ! or $n+1$ respectively yielding the results with the usual restriction on the parameters.

Some other properties of ${ }_{1} A_{1}\left(\begin{array}{l}\sigma \\ z\end{array} \mid \begin{array}{l}a \\ b\end{array} ; f(z)\right)$ will be discussed in another communication. 


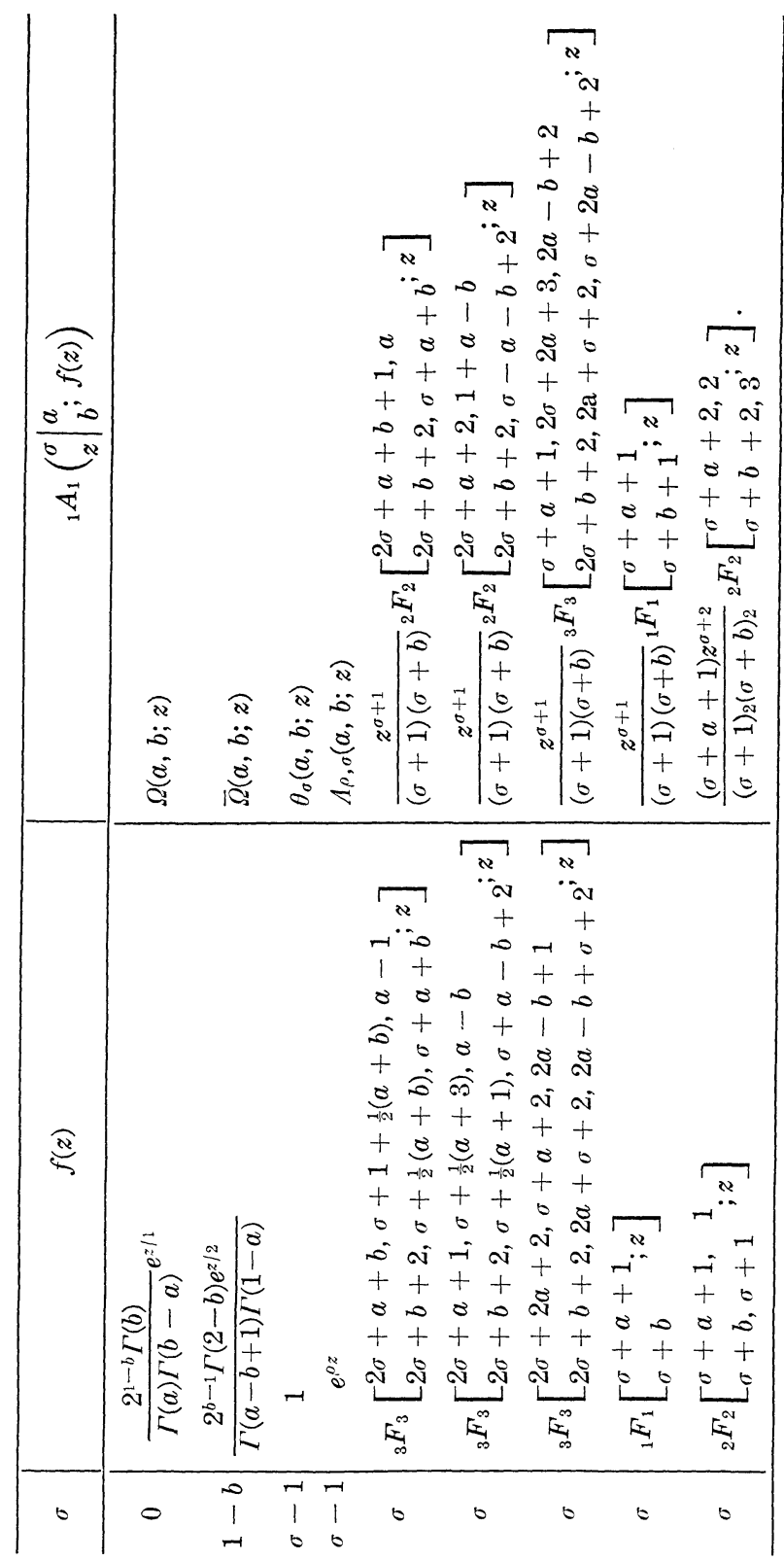

\section{REFERENCES}

1. A. W. Babister, Transcendental Functions, MacMillan (N. Y.), 1967.

2. L. Carlitz, The sum of the first $n$ terms of an ${ }_{5} F_{4}$, Bol. un. Mat. Ital. 19 (1964), 436-440.

3. T. Erber, Inequalities for hypergeometric functions, Arch. Rational Mech. Anal., 4 (1959/60), 341-351.

Received July 22, 1970. 


\section{PACIFIC JOURNAL OF MATHEMATICS}

\section{EDITORS}

\section{H. SAMELSON}

Stanford University

Stanford, California 94305

\section{R. HOBBY}

University of Washington Seattle, Washington 98105

\section{J. DugundJI}

Department of Mathematics University of Southern California Los Angeles, California 90007

RICHARD ARENS

University of California Los Angeles, California 90024

\section{ASSOCIATE EDITORS}
E. F. BECKENBACH
B. H. Neumann
F. WoLF
K. YoSHIDA

\section{SUPPORTING INSTITUTIONS}

UNIVERSITY OF BRITISH COLUMBIA CALIFORNIA INSTITUTE OF TECHNOLOGY

UNIVERSITY OF CALIFORNIA

MONTANA STATE UNIVERSITY

UNIVERSITY OF NEVADA

NEW MEXICO STATE UNIVERSITY

OREGON STATE UNIVERSITY

UNIVERSITY OF OREGON

OSAKA UNIVERSITY

\author{
UNIVERSITY OF SOUTHERN CALIFORNIA \\ STANFORD UNIVERSITY \\ UNIVERSITY OF TOKYO \\ UNIVERSITY OF UTAH \\ WASHINGTON STATE UNIVERSITY \\ UNIVERSITY OF WASHINGTON \\ * * * * \\ AMERICAN MATHEMATICAL SOCIETY \\ NAVAL WEAPONS CENTER
}

The Supporting Institutions listed above contribute to the cost of publication of this Journal, but they are not owners or publishers and have no responsibility for its content or policies.

Mathematical papers intended for publication in the Pacific Journal of Mathematics should be in typed form or offset-reproduced, (not dittoed), double spaced with large margins. Underline Greek letters in red, German in green, and script in blue. The first paragraph or two must be capable of being used separately as a synopsis of the entire paper. The editorial "we" must not be used in the synopsis, and items of the bibliography should not be cited there unless absolutely necessary, in which case they must be identified by author and Journal, rather than by item number. Manuscripts, in duplicate if possible, may be sent to any one of the four editors. Please classify according to the scheme of Math. Rev. Index. to Vol. 39. All other communications to the editors should be addressed to the managing editor, Richard Arens, University of California, Los Angeles, California, 90024.

50 reprints are provided free for each article; additional copies may be obtained at cost in multiples of 50 .

The Pacific Journal of Mathematics is published monthly. Effective with Volume 16 the price per volume (3 numbers) is $\$ 8.00$; single issues, $\$ 3.00$. Special price for current issues to individual faculty members of supporting institutions and to individual members of the American Mathematical Society: $\$ 4.00$ per volume; single issues $\$ 1.50$. Back numbers are available.

Subscriptions, orders for back numbers, and changes of address should be sent to Pacific Journal of Mathematics, 103 Highland Boulevard, Berkeley, California, 94708.

PUBLISHED BY PACIFIC JOURNAL OF MATHEMATICS, A NON-PROFIT CORPORATION

Printed at Kokusai Bunken Insatsusha (International Academic Printing Co., Ltd.), 270, 3-chome Totsuka-cho, Shinjuku-ku, Tokyo 160, Japan. 


\section{Pacific Journal of Mathematics}

\section{Vol. 40, No. $3 \quad$ November, 1972}

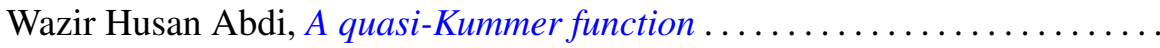

Vasily Cateforis, Minimal injective cogenerators for the class of modules of

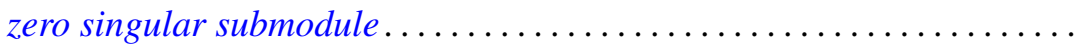

W. Wistar (William) Comfort and Anthony Wood Hager, Cardinality of

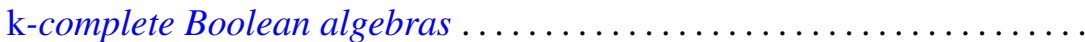

Richard Brian Darst and Gene Allen DeBoth, Norm convergence of martingales of Radon-Nikodym derivatives given a $\sigma$-lattice ..........

M. Edelstein and Anthony Charles Thompson, Some results on nearest points and support properties of convex sets in $c_{0} \ldots \ldots \ldots \ldots \ldots$

Richard Goodrick, Two bridge knots are alternating knots .

Jean-Pierre Gossez and Enrique José Lami Dozo, Some geometric properties related to the fixed point theory for nonexpansive mappings ..........

Dang Xuan Hong, Covering relations among lattice varieties .............

Carl Groos Jockusch, Jr. and Robert Irving Soare, Degrees of members of $\Pi_{1}^{0}$

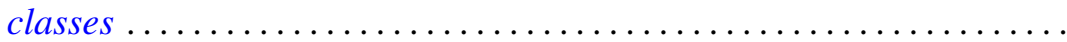

565

575

605

Leroy Milton Kelly and R. Rottenberg, Simple points in pseudoline

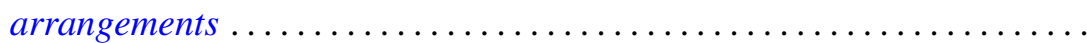

Joe Eckley Kirk, Jr., The uniformizing function for a class of Riemann surfaces....

Glenn Richard Luecke, Operators satisfying condition $\left(G_{1}\right)$ locally ... 629

T. S. Motzkin, On L $(S)$-tuples and l-pairs of matrices ... . .

Charles Estep Murley, The classification of certain classes of torsion free

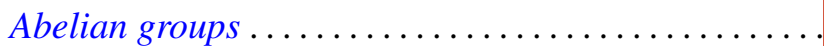

Louis D. Nel, Lattices of lower semi-continuous functions and associated topological spaces.

David Emroy Penney, II, Establishing isomorphism between tame prime

knots in $E^{3}$. . .

Daniel Rider, Functions which operate on $\mathscr{F} L_{p}(T), 1<p<2$

Thomas Stephen Shores, Injective modules over duo rings ...

Stephen Simons, A convergence theorem with boundary. .

703

Stephen Simons, Maximinimax, minimax, and antiminimax theorems and a

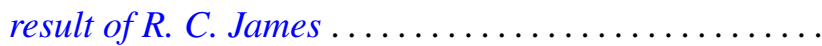

Stephen Simons, On Ptak's combinatorial lemma ........

Stuart A. Steinberg, Finitely-valued $f$-modules............

Pui-kei Wong, Integral inequalities of Wirtinger-type and fourth-order

elliptic differential inequalities .

Yen-Yi Wu, Completions of Boolean algebras with partially additive

operators ..................................

Phillip Lee Zenor, On spaces with regular $G_{\delta}$-diagonals . . . 